\title{
Aumento de la vida útil y microbiología de la carne de pavo envasada en atmósferas modificadas
}

\section{Shelf life extension and microbiology of turkey meat packaged in modified atmosphere}

\author{
Sérgio Borges Mano, ${ }^{*}$ Juan Antonio Ordóñez ${ }^{* *}$ y Gonzalo García de Fernando**
}

\begin{abstract}
Resumen
El objetivo del presente estudio fue evaluar el efecto del envasado de carne de pavo en atmósferas modificadas, así como estudiar el crecimiento de los microorganismos responsables de su alteración. Se obtuvieron asépticamente filetes de pechuga de pavo de aproximadamente $3 \times 3 \mathrm{~cm}$, se introdujeron en bolsas de plástico (Cryovac BB4L) caracterizadas por su baja permeabilidad a los gases. Las bolsas se dividieron en 4 lotes y se llenaron con aproximadamente 1,5L de aire $100 \%$, Nitrógeno $100 \%, \mathrm{CO}_{2} / \mathrm{O}_{2} 20 / 80$ y $\mathrm{CO}_{2} / \mathrm{O}_{2} 40 / 60$ y se sellaron. Finalmente, cada lote se subdividió en 2 , almacenándose uno de ellos a $1^{\circ} \mathrm{C}$ y el otro a $7^{\circ} \mathrm{C}$. A lo largo del almacenamiento se determinó la concentración de los gases y el $\mathrm{pH}$ y se realizaron los recuentos de la microbiota total, bacterias lácticas, Enterobacteriaceae, Brochothrix thermosphacta, y Pseudomonas. Los parámetros de crecimiento (fase de latencia y tiempo de generación) se determinaron mediante la ecuación de Gompertz. Los resultados han demostrado que la vida útil de la carne de pavo se prolonga cuando se almacena en atmósferas modificadas. Con la atmósfera de nitrógeno (100\%) se comprobó una prolongación de 5 días en la vida útil, independientemente de la temperatura de almacenamiento utilizada. Sin embargo, las atmósferas enriquecidas con $\mathrm{CO}_{2}$ a $1^{\circ} \mathrm{C}$ mostraron una mayor eficacia. Apenas hubo alteración en la concentración de los gases durante el período de almacenamiento. En las muestras conservadas bajo atmósfera modificada, tanto a $7 \operatorname{como}$ a $1^{\circ} \mathrm{C}$, el pH se mantuvo constante durante el período de almacenamiento. A 1 y $7^{\circ} \mathrm{C}$ las fases de latencia y los tiempos de duplicación de la microbiota total fueron progresivamente mayores en el siguiente orden: atmósfera de aire $(100 \%), \mathrm{N}_{2}$ (100\%), $\mathrm{CO}_{2} / \mathrm{O}_{2}(20 / 80)$ y $\mathrm{CO}_{2} / \mathrm{O}_{2}(40 / 60)$. De acuerdo con los resultados, se puede concluir que, tanto a $1 \mathrm{como}$ a $7^{\circ} \mathrm{C}$, la utilización de las atmósferas modificadas retardó el crecimiento de las bacterias alterantes de la carne de pavo,

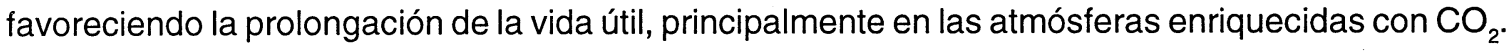

Palabras-clave: atmósferas modificadas; carne de pavo; vida útil.

\section{Introducción}

La carne fresca es un producto muy perecedero. Son los microorganismos, sobre todo las bacterias, los agentes responsables del deterioro de este alimento cuando se mantiene en refrigeración y aerobiosis. Como puede suponerse, los microorganismos descritos en la carne (Gill, 1982; McMeekin, 1982) pertenecen a diversos géneros, destacando Pseudomonas, Moraxella, Acinetobacter, Lactobacillus, Micrococcus, Aeromonas, Brochothrix y algunos géneros de la familia Enterobacteriaceae. No obstante, el crecimiento de las bacterias mesófilas se inhibe de forma muy considerable, si no totalmente, a temperaturas de refrigeración, mientras que el de otros microorganismos como Brochothrix thermosphacta, lactobacilos y algunas enterobacterias es más lento que el de los psicrotrofos aerobios del grupo Pseudomonas / Acinetobacter/Moraxella / Alteromonas, que son, por regla general, las bacterias que prevalecen en las carnes y, si las condiciones de almacenamiento lo permiten, provocan su deterioro. En realidad, Pseudomonas spp. suelen ser los agentes responsables de la alteración, aunque casi siempre en compañía de otros miembros del grupo mencionado. La alteración de la carne se produce cuando se alcanza la tasa de $10^{7}$ ufc/cm ${ }^{2}$ (Dainty et al., 1983) y se manifiesta por olores desagradables y limosidad superficial derivados del crecimiento microbiano.

Aunque la vida útil de la carne mantenida en refrigeración depende de varios factores (tamaño de la pieza de carne, carga microbiana inicial, temperatura de almacenamiento etc.) suele admitirse que muy difícilmente pueden sobrepasarse los 12-15 días de almacenamiento en refrigeración, en las mejores condiciones, sin que aparezcan signos de alteración. Este tiempo es más que suficiente para el suministro local, pero es complicado

*Departamento de Tecnologia dos Alimentos, Faculdade de Veterinária, UFF. Rua Vital Brazil Filho, 64 - 24230-340 - Niterói - Brasil.

*^Departamento de Nutrición y Bromatología III (Higiene y Tecnología de los Alimentos), Facultad de Veterinaria, U.C.M. 28040 - Madrid - España. 
alcanzar esas condiciones "ideales", además existe el comercio internacional, la venta al detalle en zonas alejadas de las productoras, la manipulación de la carne, su despiece, fileteo y envasado en bandejas de poliestireno recubiertas de un plástico permeable al oxígeno del aire, etc. Todos estos factores obligan a poner a la venta la carne inmediatamente después de su recepción y su vida útil en las estanterías de los supermercados o en los mostradores de las carnicerías puede ser muy corta. Por consiguiente, merece la pena prolongarla.

El $\mathrm{CO}_{2}$ se ha utilizado comercialmente para inhibir el crecimiento microbiano y alargar la vida útil de la carne desde la década de 1930, pero no fue hasta los años 50 y 60 , coincidiendo con el auge de la industria de los plásticos, cuando comenzó a investigarse la posibilidad de envasar carne en atmósferas modificadas con esa finalidad. En los años 70, numerosos investigadores establecieron que las atmósferas enriquecidas en $\mathrm{CO}_{2}(40-20 \%)$ y $\mathrm{O}_{2}$ $(60-80 \%)$ eran las mejores para ampliar la vida útil de las carnes de vacuno (Clark, Lentz, 1973; Taylor, MacDougall, 1973), cerdo (Ordóñez, Ledward, 1977) y cordero (Newton et al., 1977) e incluso carne picada de cerdo (López Lorenzo et al., 1980), estudiándose concomitantemente la microbiología de estas carnes envasadas en atmósferas modificadas. Hay que tener en cuenta que todas esas carnes suelen tener un pH en torno a 5,5 y quizás sea éste el motivo de que los resultados de los autores antes mencionados no difieren mucho en cuanto a la microbiología y ampliación de la vida útil.

Las carnes de ave, a diferencia de las anteriores, se caracterizan por presentar un $\mathrm{pH}$ más elevado. Los responsables de la alteración de estas carnes suelen ser los mismos que los que deterioran las carnes rojas. El efecto del envasado de carne de pollo cruda y cocinada en atmósferas modificadas en sus características sensoriales y vida útil ha sido estudiado por Hotchkiss et al. (1985), quienes comprobaron una considerable prolongación de la vida útil con el envasado en atmósferas enriquecidas en más de un $20 \%$ de $\mathrm{CO}_{2}$. A diferencia de las carnes rojas, puede decirse que el envasado de carne de aves en atmósfera modificada no influye en su color, sobre todo cuando se mantiene la piel en las piezas. Sin embargo, en el caso de filetes o porciones sin piel, existe la posibilidad de hacer más atractivo el color de la carne mediante la inclusión de $\mathrm{O}_{2}$ en la atmósfera (Parry, 1993). A este respecto, cuando Mead (1983) evaluó diferentes mezclas de gases para ampliar la vida útil de filetes de pavo utilizando niveles de $\mathrm{O}_{2}$ del 10 al $20 \%$, sólo observó una mejora del color de la carne con la concentración más elevada de gas, cuando aparecía un atrayente tono rosa asalmonado. No obstante, hay una falta de conocimientos sobre la microbiota responsable de la alteración de esta carne envasada en atmósferas modificadas, por lo que el presente trabajo pretende llenar esta laguna, además de comprobar el efecto del envasado en la conservación de esta carne.

\section{Material y métodos}

\section{Operaciones previas}

Todas las operaciones se llevaron a cabo con material previamente esterilizado.

En primer lugar se procedió a la retirada de la piel del pavo y seguidamente se extrajo la pechuga. Una vez obtenida ésta, se cortó transversalmente el músculo en filetes de aproximadamente $0,5 \mathrm{~cm}$ de espesor con un cuchillo que previamente había sido flameado. Del centro de este filete se obtuvo asépticamente uno de aproximadamente $3 \times 3$ $\mathrm{cm}$, es decir, $18 \mathrm{~cm}^{2}$ de superficie.

Las muestras se envasaron en bolsas BB4L (un filete por bolsa), que a continuación se llenaron con las atmósferas de: $100 \%$ aire, $100 \%$ nitrógeno, $20 / 80 \mathrm{CO}_{2} / \mathrm{O}_{2}$ ó 40/60 $\mathrm{CO}_{2} / \mathrm{O}_{2}$. La relación utilizada de gas/muestra fue de $\sim$ 150:1, lo que correspondió $~ 1,5 \mathrm{~L}$ de gas por bolsa. La incubación de las muestras se realizó en cámaras frigoríficas termostatadas a 1 ó $7^{\circ} \mathrm{C}$.

\section{Métodos microbiológicos}

La toma de muestras se realizó diariamente o en días alternos, de acuerdo con la temperatura de incubación, la atmósfera utilizada y resultados de días anteriores.

Justo antes de envasar las muestras, se recogieron aleatoriamente 2 filetes para determinar su $\mathrm{pH}$ y su carga microbiana inicial.

Los filetes mantenidos en atmósfera de $100 \%$ aire, $100 \%$ nitrógeno, $20 / 80 \mathrm{CO}_{2} / \mathrm{O}_{2}$ y $40 / 60 \mathrm{CO}_{2} / \mathrm{O}_{2}$ se trasladaron al laboratorio en las mismas bolsas de plástico usadas en la incubación. Tras analizar la composición de los gases mediante un analizador combinado de gases $\left(\mathrm{O}_{2}+\mathrm{CO}_{2}\right)$, se procedió a abrir la bolsa en la campana de flujo laminar, tomando las muestras a continuación.

Los filetes se introdujeron en bolsas estériles para "Stomacher" que contenían $25 \mathrm{~mL}$ de solución salina $(0,85 \%)$ esterilizada y a continuación se procedió a su homogeneización durante $1 \mathrm{~min}$.

Los medios de cultivo empleados para los recuentos fueron:

a) Agar para recuento en placa (PCA). Se empleó como medio para el recuento de la microbiota total. Incubación a $32^{\circ} \mathrm{C}$, de 24 a 48 horas.

b) Agar de Man, Rogosa y Sharpe (MRS). Se utilizó para el recuento de bacterias lácticas (Man et al., 1960), ajustando el pH a 5,6 con ácido acético glacial y utilizando doble capa de agar. Incubación a $32^{\circ} \mathrm{C}$, de 48 a 72 horas.

c) Agar violeta rojo bilis glucosa (VRBG). Se usó para el recuento de enterobacterias. Incubación a $32^{\circ} \mathrm{C}$ durante 24 horas. 
d) Agar sulfato de estreptomicina (50\%), cicloheximida (5 $\%)$, acetato de talio (5\%) (STAA suministrado por Oxoid). Se utilizó para el recuento de Brochothrix thermosphacta. Incubación a $24^{\circ} \mathrm{C}$, de 48 a 72 horas.

e) Agar selectivo para Pseudomonas (PSD) con "Pseudomonas C-F-C Suplemento Selectivo" (cetrimida al $1 \%$, fucidina al 1 \% y cefaloridina al $5 \%$ ) suministrado por Oxoid. Se empleó para el recuento de Pseudomonas spp. Incubación a $24^{\circ} \mathrm{C}$, de 48 a 72 horas. Este agar se denominará a lo largo del trabajo con las siglas PSD.

La preparación de los medios de cultivo se llevó a cabo de acuerdo con las instrucciones de las casas suministradoras (Difco y Oxoid). Cuando fue necesario, se esterilizaron durante $15 \mathrm{~min}$. a $121^{\circ} \mathrm{C}$ antes de su uso. En el caso de los medios STAA y agar PSD se añadió de forma aséptica el suplemento específico después de la esterilización del medio base.

Se prepararon diluciones decimales en solución salina $(0,85$ $\%$ de $\mathrm{NaCl}$ ) estéril a partir de los filetes.

De acuerdo con el número de microorganismos viables esperados, se tomó $1 \mathrm{~mL}$ de las diluciones deseadas y se depositó en placas de Petri. A continuación se vertió una cantidad suficiente de agar a unos $45^{\circ} \mathrm{C}$ para cubrir el fondo de la placa; después, éstas se agitaron suavemente para homogeneizar la muestra y el agar. En los recuentos de bacterias lácticas en agar MRS, una vez solidificado, se añadió otra capa de medio para crear condiciones microaerófilas que favorecieran el crecimiento de las bacterias lácticas. En todos los casos se sembraron 2 placas de cada dilución.

Tras el período de incubación correspondiente se efectuó el recuento de colonias presentes en las placas, considerando las que contenían entre 30 y 300 colonias. El recuento se dividió por 18 (área total del filete en $\mathrm{cm}^{2}$ ), con lo que los resultados finales se expresaron en log ufc/cm ${ }^{2}$ de muestra.

\section{Determinación del $\mathrm{pH}$}

Después de la toma de muestras para las determinaciones microbiológicas se efectuaron, por muestra, 5 determinaciones de $\mathrm{pH}$ introduciendo el electrodo en la propia bolsa de "Stomacher", donde se había homogeneizado el filete con solución salina estéril. El valor del pH se obtuvo de la media aritmética de las medidas.

\section{Análisis de los gases}

El análisis de la atmósfera que rodeaba la carne se realizó justamente antes de la apertura de la bolsa para el análisis microbiológico.

La determinación cuantitativa de los componentes de la atmósfera se hizo con un analizador combinado de gases $\left(\mathrm{O}_{2}+\mathrm{CO}_{2}\right)$ marca "Abiss" mod. GT12 pinchando la bolsa con la aguja unida al analizador. Deben esperarse unos segundos hasta que la medida de los gases se estabilice.

El nitrógeno fue estimado por la diferencia entre el $100 \%$ y la suma de los porcentajes de $\mathrm{O}_{2}$ y $\mathrm{CO}_{2}$, asumiendo que la atmósfera sólo se componía de estos 3 gases.

\section{Análisis de los resultados}

Los datos de los recuentos, una vez organizados en una base de datos, se analizaron mediante la ecuación de Gompertz, modificada por Gibson y col. (1987), para describir el crecimiento de una población bacteriana. Se utilizó para tal, un programa informático diseñado por el Dr. József Baranyi en el "Institute of Food Research (Reading Laboratory, UK)".

\section{Resultados y discusión}

\section{Cambio en la composición de los gases}

La composición de las atmósferas no cambió en ninguna muestra durante los distintos periodos de almacenamiento (datos no mostrados).

No son muchos los trabajos cuyo objetivo haya sido el estudio de las variaciones de la composición de los gases durante el almacenamiento de carne en atmósferas modificadas. Además, en algunas ocasiones se han presentado resultados contradictorios. Mientras que Seideman et al. (1980) indicaron que la concentración de $\mathrm{CO}_{2}$ disminuía durante el almacenamiento de carne, Spahl et al. (1981) aseguraron que los niveles de $\mathrm{CO}_{2}$ aumentaban. Por su parte, Fang y Lin (1994a) observaron una disminución del $\mathrm{O}_{2}$ y un aumento del $\mathrm{CO}_{2}$ durante el almacenamiento a $4^{\circ} \mathrm{C}$ de carne de cerdo cocinada y envasada en aire.

Como ya se ha dicho, en nuestro estudio la atmósfera no se modificó, o mejor dicho, con el sistema de medida de gases que se ha empleado, no se detectó variación alguna. La sensibilidad del analizador de gases aquí utilizado (Abiss mod. GT12) no es suficiente para valorar las pequeñas modificaciones que, seguro, ocurrieron merced a la actividad microbiológica, actividad bioquímica de la carne y permeabilidad del plástico. Además, otro factor decisivo fue la relación volumen de gas / masa de alimento, en torno a 150/1, cuando los niveles comerciales recomendados son del orden de 2/1 (Rönner, 1994) a 3/1 (Holland, 1980), obviamente por economía de espacio. La elección, en el presente estudio, de una relación entre volumen de gas y masa de carne tan alejada de la práctica comercial fue precisamente evitar que la modificación de la atmósfera durante el almacenamiento enmascarase el efecto de la propia atmósfera en el comportamiento de la microbiota alterante. En otras palabras, con los medios que se disponía, se pretendían crear unas condiciones próximas a las de las atmósferas controladas y, de hecho, así fue.

Puede decirse que, aunque es habitual apreciar modificaciones en la composición de la atmósfera que cir- 
cunda al alimento, sobre todo en aquellos con mayor actividad metabólica (p.e. hortalizas y frutas, debido a la actividad respiratoria de las mismas), en este trabajo no se apreciaron variaciones.

\section{Evolución del $\mathrm{pH}$}

Las muestras de carne aquí empleadas tuvieron $\mathrm{pHs}$ iniciales rondando el valor de 6,0 (Figuras 1 y 2 ).
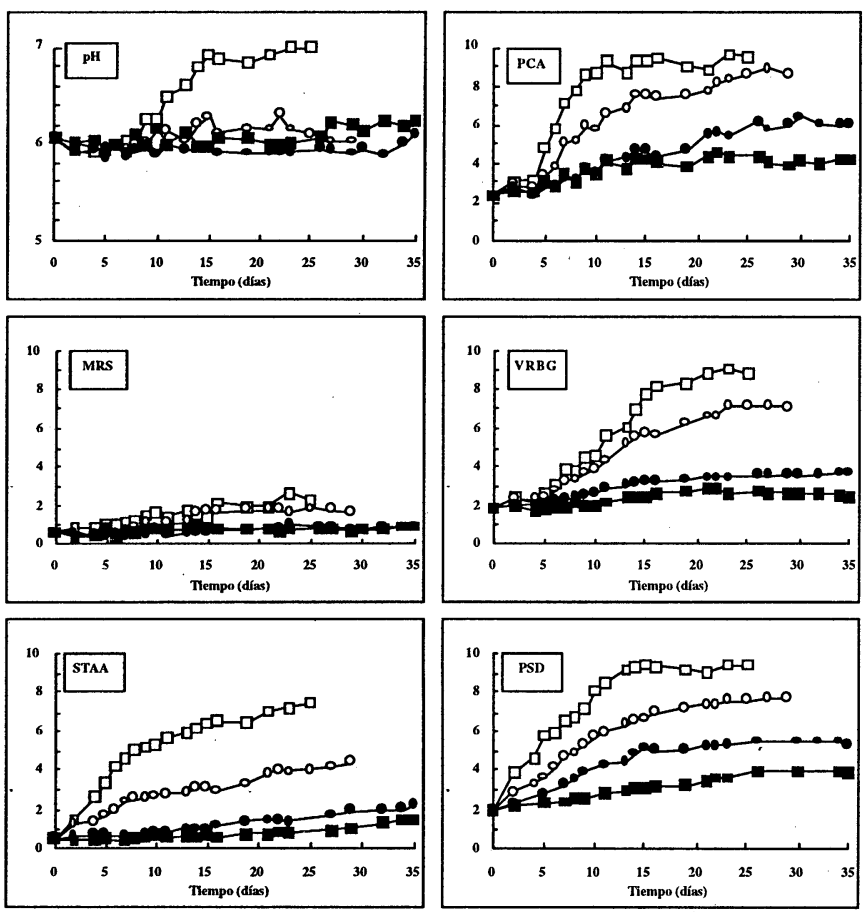

Figura 1: Evolución del $\mathrm{pH}$, microbiota total (PCA), bacterias lácticas (MRS), enterobacterias (VRBG), Brochothrix thermosphacta (STAA) y Pseudomonas spp. (PSD) en carne de pavo almacenada en $100 \%$ aire (o), $100 \% \mathrm{~N}_{2}(\mathrm{i}), 20 / 80 \mathrm{CO}_{2} / \mathrm{O}_{2}$ (I) y $40 / 60 \mathrm{CO}_{2} / \mathrm{O}_{2}$ (n) a $1^{\circ} \mathrm{C}$.

En el presente trabajo no se apreciaron variaciones del $\mathrm{pH}$ al principio de las experiencias, aunque diversos autores (Clark y Lentz, 1973 ; Daniels et al., 1985 ; McMullen y Stiles, 1991) han observado disminuciones de este parámetro como consecuencia de la solubilidad del $\mathrm{CO}_{2}$ en los alimentos. No obstante, diversas experiencias de otros autores muestran la invariabilidad del $\mathrm{pH}$. Así, no se han observado modificaciones del pH en salmón envasado en atmósferas enriquecidas en $\mathrm{CO}_{2}$ (Fey y Regenstein, 1982 ; López-Gálvez et al., 1995), carne de cordero envasada en vacío, $20 / 80 \mathrm{CO}_{2} / \mathrm{O}_{2}, 50 / 50 \mathrm{CO}_{2} / \mathrm{N}_{2}$ y $100 \%$ de $\mathrm{CO}_{2}$ (Doherty et al., 1995; Sheridan et al., 1995 ; Doherty et al., 1996) y vacuno en $100 \%$ de $\mathrm{CO}_{2}$ (Avery et al., 1995). Quizás se deba a la capacidad tampón de muchos de los componentes de la carne que, aunque débil, puede ser suficiente para contrarrestar el efecto del $\mathrm{CO}_{2}$ disuelto.

En cambio, cuando el alimento se mantiene en aire, es normal que el $\mathrm{pH}$ aumente, coincidiendo con recuentos
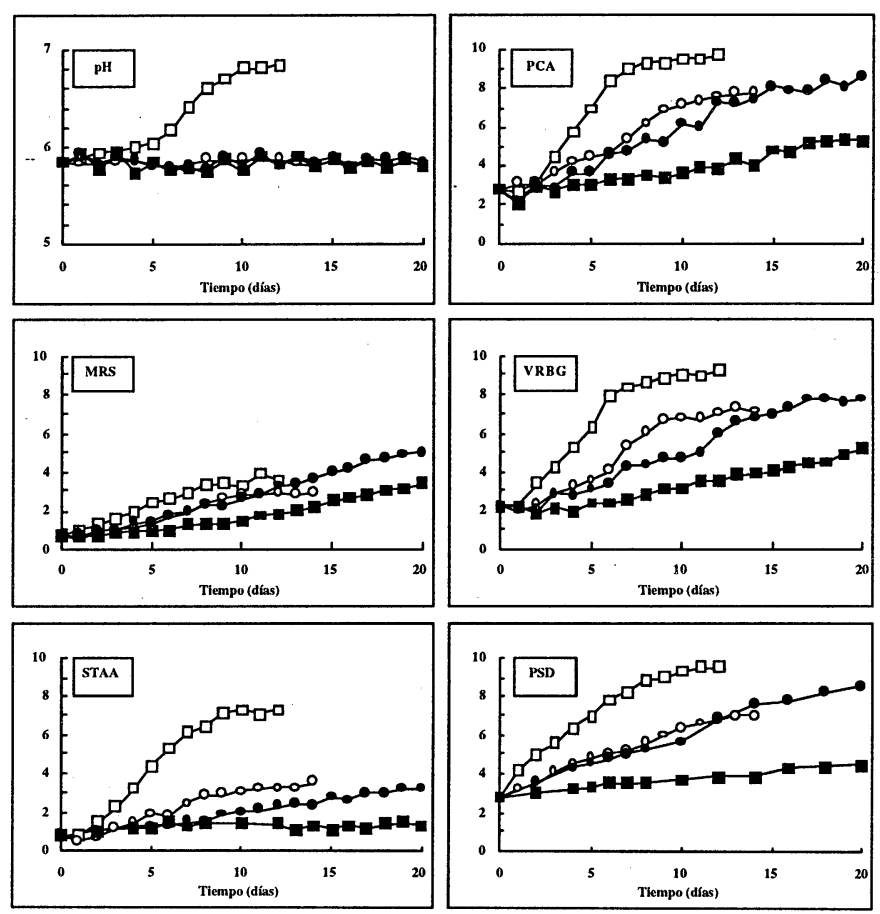

Figura 2: Evolución del pH, microbiota total (PCA), bacterias lácticas (MRS), enterobacterias (VRBG), Brochothrix thermosphacta (STAA) y Pseudomonas spp. (PSD) en carne de pavo almacenada en $100 \%$ aire (o), $100 \% \mathrm{~N}_{2}(\mathrm{i}), 20 / 80 \mathrm{CO}_{2} / \mathrm{O}_{2}(\mathrm{l})$ y $40 / 60 \mathrm{CO}_{2} / \mathrm{O}_{2}(n)$ a $7^{\circ} \mathrm{C}$.

totales superiores a $10^{7}$ ufc/cm ${ }^{2}$ y la alteración del alimento (Figuras 1 y 2 ). Estos cambios se deben, posiblemente, a la generación de sustancias básicas derivadas del crecimiento de pseudomonas y otros microorganismos afines. A este respecto, Farrag y Marth (1989a), trabajando con medio de cultivo (triptosa) inoculado con diversas especies de pseudomonas correlacionaron el aumento del $\mathrm{pH}$ con el crecimiento de las pseudomonas.

$\mathrm{El} \mathrm{pH}$ de la mayor parte de las muestras envasadas en atmósferas modificadas no varió a lo largo de todo el tiempo que duraron las diferentes experiencias. No obstante, también se han detectado ciertos aumentos de los valores del $\mathrm{pH}$ en algunas muestras envasadas en atmósferas modificadas, aunque siempre menos llamativos que los observados en la carne envasada aeróbicamente; específicamente a $1^{\circ} \mathrm{C}$ en nitrógeno y a $7^{\circ} \mathrm{C}$ envasada tanto en $20 / 80 \mathrm{CO}_{2} / \mathrm{O}_{2}$ como en $40 / 60 \mathrm{CO}_{2} / \mathrm{O}_{2}$. En todos los casos, el aumento de $\mathrm{pH}$ se hizo evidente tras cruzar el umbral de la vida útil de la carne.

De lo expuesto puede decirse que el $\mathrm{pH}$ de la carne en atmósfera de aire empieza a aumentar cuando el número de microorganismo es muy elevado, coincidiendo con la alteración del producto. En el envasado en atmósfera modificada, lo habitual es que el pH se mantenga constante, al menos durante la vida útil del alimento. 


\section{Microbiota Total (MT)}

Los recuentos iniciales de la microbiota total (MT) al principio de las experiencias fueron bajos, siempre inferiores a $10^{3} \mathrm{ufc} / \mathrm{cm}^{2}$ (Tablas 1 y 2). Estos recuentos iniciales tan bajos son un índice de las buenas condiciones en que se manipularon las muestras, mucho mejores que las habituales en un matadero, sala de despiece o carnicería, donde se obtienen unas tasas microbianas, en condiciones prácticas óptimas, más elevadas. Como puede apreciarse, los recuentos iniciales de las muestras almacenadas a 1 y $7^{\circ} \mathrm{C}$ no fueron iguales. Esto se debió a la imposibilidad material de partir de la misma materia prima, debido a la limitación de espacio en los armarios refrigeradores o la imposibilidad de manipular un número elevado de muestras.
La fase de latencia de una población microbiana indica el tiempo que tarda esa población en comenzar a multiplicarse activamente. En este trabajo se ha calculado aplicando la ecuación de Gompertz. Desgraciadamente, la fase de latencia no es constante ni siquiera en sistemas modelos, ya que no sólo depende de la especie microbiana sino también de la "historia" del microorganismo o grupo microbiano en cuestión, por lo que para estandarizar làs fases de latencia de un cultivo puro hay que normalizar estrictamente su procedencia. Además, cuando ésta se calcula, la microbiota ya ha comenzado a crecer y saber en ese momento el tiempo que han tardado en comenzar el desarrollo carece de importancia. No obstante, siempre pueden hacerse algunas generalizaciones. Cuanto más

Tabla 1: Vida útil y parámetros de crecimiento de la microbiota de carne de pavo envasada en diferentes atmósferas y mantenida a $1^{\circ} \mathrm{C}$ durante 25 (aire $\left.100 \%\right), 29\left(\mathrm{~N}_{2} 100 \%\right)$ ó 35 días $\left(\mathrm{CO}_{2} / \mathrm{O}_{2} 20 / 80, \mathrm{CO}_{2} / \mathrm{O}_{2} 40 / 60\right)$.

\begin{tabular}{|c|c|c|c|c|c|c|c|}
\hline ATMÓSFERAS & Vida útil ${ }^{\mathrm{a}}$ & $\begin{array}{c}\text { PARÁMETROS } \\
\text { DE CRECIMIENTO }\end{array}$ & $\begin{array}{l}\text { Microbiota } \\
\text { Total }\end{array}$ & $\begin{array}{l}\text { Bacterias } \\
\text { Lácticas }\end{array}$ & $\begin{array}{c}\text { Entero- } \\
\text { bacterias }\end{array}$ & $\begin{array}{l}\text { Brochothrix } \\
\text { thermosphacta }\end{array}$ & PSD \\
\hline & & Microbiota inicial $^{b}$ & 2,4 & 0,6 & 1,8 & 0,5 & 2,0 \\
\hline \multirow[t]{3}{*}{ Aire (100\%) } & \multirow[t]{3}{*}{10} & Fase de latencia ${ }^{c}$ & 3,2 & 6,5 & 5,6 & 3,7 & 2,5 \\
\hline & & Valor $\mathrm{g}^{\mathrm{c}}$ & 0,6 & 4,7 & 0,5 & 0,6 & 0,6 \\
\hline & & Carga final ${ }^{b}$ & 9,5 & 2,2 & 8,8 & 7,5 & 9,4 \\
\hline \multirow[t]{3}{*}{$\mathrm{N}_{2}(100 \%)$} & \multirow[t]{3}{*}{15} & Fase de latencia $\mathrm{c}$ & 4,0 & 11,8 & 7,0 & 6,7 & 3,8 \\
\hline & & Valor $\mathrm{g}^{\mathrm{c}}$ & 0,7 & 7,4 & 0,7 & 0,9 & 0,7 \\
\hline & & Carga final $b$ & 8,6 & 1,6 & 7,1 & 4,4 & 7,7 \\
\hline \multirow[t]{3}{*}{$\mathrm{CO}_{2} / \mathrm{O}_{2} 20 / 80$} & \multirow[t]{3}{*}{$\mathrm{d}$} & Fase de latencia ${ }^{c}$ & 15,0 & 20,1 & 11,0 & 10,0 & 3,6 \\
\hline & & Valor $\mathrm{g}^{\mathrm{c}}$ & 1,8 & 8,0 & 5,1 & 0,7 & 2,4 \\
\hline & & Carga final ${ }^{b}$ & 6,0 & 0,9 & 3,7 & 2,2 & 5,4 \\
\hline \multirow[t]{3}{*}{$\mathrm{CO}_{2} / \mathrm{O}_{2} 40 / 60$} & \multirow[t]{3}{*}{ d } & Fase de latencia ${ }^{\mathrm{c}}$ & 17,2 & 24,7 & 14,0 & 11,0 & 4,0 \\
\hline & & Valor $\mathrm{g}^{\mathrm{c}}$ & 2,6 & 8,4 & 8,0 & 0,6 & 2,3 \\
\hline & & Carga final ${ }^{b}$ & 4,2 & 0,9 & 2,4 & 1,5 & 3,9 \\
\hline
\end{tabular}

${ }^{a}$ Vida útil o tiempo (días) que se tarda en alcanzar la tasa de $10^{7} \mathrm{UFC} / \mathrm{cm}^{2}$. ${ }^{\mathrm{b}}$. Valores expresados en log UFC/ $\mathrm{cm}^{2}$. c. Valores expresados en días.

d La carga final no alcanzó la tasa de $10^{7} \mathrm{UFC} / \mathrm{cm}^{2}$ tras 35 días de almacenamiento. PSD - Microorganismos crecidos en medio selectivo para Pseudomonas spp. a $20^{\circ} \mathrm{C}, 72 \mathrm{~h}$.

baja es la temperatura de almacenamiento la fase de latencia es más prolongada; de igual modo, cuanto más selectiva es la atmósfera, más tiempo tarda la microbiota en comenzar su multiplicación. En cualquier caso, este parámetro siempre permite deducir algunos hechos. En este trabajo las fases de latencia (Tablas 1 y 2 ) han sido útiles para comparar la adaptación de una determinada microbiota a las atmósferas en que crecen, siempre y cuando la contaminación inicial fuera la misma, ya que los precedentes de esa microbiota eran idénticos.

A diferencia del parámetro anterior, los tiempos de duplicación, definitorio del crecimiento de un microorganismo 
Tabla 2: Vida útil y parámetros de crecimiento de la microbiota de carne de pavo envasada en diferentes atmósferas y mantenida a $7^{\circ} \mathrm{C}$ durante 12 (aire $\left.100 \%\right), 14\left(\mathrm{~N}_{2} 100 \%\right)$ ó 20 días $\left(\mathrm{CO}_{2} / \mathrm{O}_{2} 20 / 80, \mathrm{CO}_{2} / \mathrm{O}_{2} 40 / 60\right)$.

\begin{tabular}{|c|c|c|c|c|c|c|c|}
\hline ATMÓSFERAS & Vida útil ${ }^{\mathrm{a}}$ & $\begin{array}{c}\text { PARÁMETROS } \\
\text { DE CRECIMIENTO }\end{array}$ & $\begin{array}{l}\text { Microbiota } \\
\text { Total }\end{array}$ & $\begin{array}{l}\text { Bacterias } \\
\text { Lácticas }\end{array}$ & $\begin{array}{l}\text { Entero- } \\
\text { bacterias }\end{array}$ & $\begin{array}{l}\text { Brochothrix } \\
\text { thermosphacta }\end{array}$ & PSD \\
\hline & & Microbiota inicial $^{b}$ & 2,8 & 0,7 & 2,2 & 0,8 & 2,8 \\
\hline \multirow[t]{3}{*}{ Aire (100\%) } & \multirow[t]{3}{*}{5} & Fase de latencia ${ }^{c}$ & 1,7 & 1,9 & 1,4 & 1,6 & 0,5 \\
\hline & & Valor $\mathrm{g}^{\mathrm{c}}$ & 0,2 & 0,6 & 0,2 & 0,3 & 0,4 \\
\hline & & Carga final $^{b}$ & 9,7 & 3,6 & 9,2 & 7,3 & 9,5 \\
\hline \multirow[t]{3}{*}{$\mathrm{N}_{2}(100 \%)$} & \multirow[t]{3}{*}{10} & Fase de latencia ${ }^{c}$ & 2,4 & 3,6 & 4,0 & 6,9 & 2,0 \\
\hline & & Valor $\mathrm{g}^{\mathrm{c}}$ & 0,5 & 0,6 & 0,3 & 0,6 & 0,9 \\
\hline & & Carga final ${ }^{b}$ & 7,8 & 2,9 & 7,1 & 3,5 & 7,0 \\
\hline \multirow[t]{3}{*}{$\mathrm{CO}_{2} / \mathrm{O}_{2} 20 / 80$} & \multirow[t]{3}{*}{12} & Fase de latencia ${ }^{c}$ & 2,9 & 7,3 & 2,5 & 5,1 & 3,1 \\
\hline & & Valor $\mathrm{g}^{\mathrm{c}}$ & 0,6 & 0,6 & 0,7 & 0,9 & 0,8 \\
\hline & & Carga final ${ }^{b}$ & 8,6 & 5,0 & 7,7 & 3,2 & 8,5 \\
\hline \multirow[t]{3}{*}{$\mathrm{CO}_{2} / \mathrm{O}_{2} 40 / 60$} & \multirow[t]{3}{*}{ d } & Fase de latencia ${ }^{c}$ & 4,1 & 7,0 & 8,9 & 11,0 & 10,1 \\
\hline & & Valor $\mathrm{g}^{\mathrm{c}}$ & 2,5 & 1,2 & 1,2 & 1,0 & 1,5 \\
\hline & & Carga final ${ }^{b}$ & 5,3 & 3,4 & 5,2 & 1,3 & 4,8 \\
\hline
\end{tabular}

a Vida útil o tiempo (días) que se tarda en alcanzar la tasa de $10^{7} \mathrm{UFC} / \mathrm{cm}^{2}$. b Valores expresados en log UFC/ $\mathrm{cm}^{2}$. ${ }^{\mathrm{c}}$ Valores expresados en días. 'La carga final no alcanzó la tasa de $10^{7} \mathrm{UFC} / \mathrm{cm}^{2}$ tras 20 días de almacenamiento. PSD - Microorganismos crecidos en medio selectivo para Pseudomonas spp. a $20^{\circ} \mathrm{C}, 72 \mathrm{~h}$.

es constante, siempre que las condiciones sean idénticas; es decir, misma cepa, sustrato, temperatura, atmósfera, etc. Como era de esperar, a $1^{\circ} \mathrm{C}$ los tiempos de duplicación de la MT fueron más prolongados que a $7^{\circ} \mathrm{C}$. También se esperaba que al hacerse más selectiva la atmósfera, la microbiota tardase más en multiplicarse. Esta segunda afirmación se comprobó en las 2 temperaturas estudiadas. A este respecto, cabe señalar que el efecto del $\mathrm{CO}_{2}$ es más intenso conforme disminuye la temperatura, por lo que es lógico que el efecto de las atmósferas sea más notable a 1 que a $7^{\circ} \mathrm{C}$.

Debe recalcarse la importancia de la microbiota inicial en los microorganismos que después prevalecerán en el alimento y, sobre todo, cuando se trata de atmósferas modificadas. Si se comparan los tiempos de duplicación de la MT obtenidos en las experiencias en aire, tanto a 1 como a $7^{\circ} \mathrm{C}$, se comprueba que fluctuaron entre 0,2 y 0,6 días, $y$ que siempre hubo crecimiento. En cambio, con las atmósferas enriquecidas en $\mathrm{CO}_{2} / \mathrm{O}_{2}$ las diferencias fueron mayores.

No son muchos los trabajos que han determinado el tiempo de duplicación de la MT en atmósferas modificadas. Manu-
Tawiah et al. (1993) afirmaron que la microbiota aerobia desarrollada en chuletas de cerdo a $4^{\circ} \mathrm{C}$ presentaba unos tiempos de duplicación, en una experiencia, de 0,8 días en aire y algo más de 6 en todas las atmósferas que estudiaron: vacío, 20/80 $\mathrm{CO}_{2} / \mathrm{N}_{2}, 40 / 60 \mathrm{CO}_{2} / \mathrm{N}_{2}$ y $40 / 10 / 50$ $\mathrm{CO}_{2} / \mathrm{O}_{2} / \mathrm{N}_{2}$, mientras que en otras obtuvieron valores de 1,6 días en aire y entre 4,6 y 4,9 días en las otras atmósferas. Estos datos no contradicen en absoluto los hallazgos de este trabajo.

El estudio de las Tablas 1 y 2 muestra que los recuentos de la MT en fase estacionaria fueron mayores en aire, después en $\mathrm{N}_{2}, 20 / 80 \mathrm{CO}_{2} / \mathrm{O}_{2} \mathrm{y}$, finalmente, menores en $40 / 60 \mathrm{CO}_{2} / \mathrm{O}_{2}$. Es decir, conforme la atmósfera se hace más selectiva, menor es el número de microorganismos al final de la fase exponencial de crecimiento. Este hecho conduce, en algunos casos, a no sobrepasar el umbral de la vida útil desde el punto de vista microbiano; por ejemplo la MT de los lotes envasados en $20 / 80 \mathrm{CO}_{2} / \mathrm{O}_{2}$ y $40 / 60$ $\mathrm{CO}_{2} / \mathrm{O}_{2}$ y almacenados a $1^{\circ} \mathrm{C}$ tienen tiempos de duplicación de 1,8 y 2,6 , respectivamente, y sus recuentos en fase estacionaria fueron de $10^{6}$ y $1,6 \times 10^{4} \mathrm{ufc} / \mathrm{cm}^{2}$, respectivamente. 


\section{Vida útil}

Como era de esperar, la modificación de la atmósfera prolongó la vida útil de la carne (tiempo necesario para alcanzar un recuento de $10^{7} \mathrm{ufc} / \mathrm{cm}^{2}$ ), siguiendo el orden lógico, de menos a más prolongada: aire, $100 \%$ de $\mathrm{N}_{2}$, $20 / 80 \mathrm{CO}_{2} / \mathrm{O}_{2}$ y $40 / 60 \mathrm{CO}_{2} / \mathrm{O}_{2}$. Obviamente, el efecto de las atmósferas modificadas, sobre todo las enriquecidas en $\mathrm{CO}_{2}$, se potencia al reducir la temperatura de almacenamiento, como resultado del sinergismo existente entre estos dos factores, como ya apuntaron, entre otros, Ordóñez y Ledward (1977), Enfors et al. (1979), Blickstad y Molin (1983), Farber (1991), Marshall et al. (1991) y Nissen et al. (1996). Este efecto sinérgico impidió, en algún caso, alcanzar la tasa de $10^{7} \mathrm{ufc} / \mathrm{cm}^{2}$ tras almacenar la carne (Tablas 1 y 2) durante aproximadamente un mes. Esto no significa que la carne envasada en atmósferas enriquecidas en $\mathrm{CO}_{2}$ pueda almacenarse tiempos tan prolongados a temperaturas de refrigeración. Téngase en cuenta que la vida útil de un alimento no puede determinarse sólo desde el punto de vista microbiológico, sino también desde el de sus propiedades sensoriales, y, en los casos antes citados, la carne mostraba un ablandamiento excesivo tras tan prolongados tiempos de almacenamiento, muy posiblemente causado por enzimas endógenas de la carne.

Es bien conocido que uno de los factores decisivos en la vida útil de un alimento es su tasa microbiana inicial. Cuanto más elevada, más corta es la vida útil. No obstante, hay que considerar que más importante que la concentración microbiana puede ser la adaptación de la microbiota presente a las condiciones que va a encontrar en el alimento y que le permitirán multiplicarse. Es obvio que la presencia masiva de microorganismos muy sensibles al $\mathrm{CO}_{2}$ en una carne envasada en una atmósfera con el $40 \%$ de ese gas no podrá multiplicarse y tendrá poca relevancia en la vida útil del producto. En cambio, una pequeña cantidad de bacterias psicrotrofas resistentes al $\mathrm{CO}_{2}$ pueden multiplicarse activamente y provocar la alteración del alimento en un tiempo corto.

De lo expuesto aquí puede decirse que la suma de refrigeración y envasado en atmósferas modificadas, además de impedir el crecimiento de determinados microorganismos, prolongan las fases de latencia (a pesar de la relativa importancia de este parámetro en la práctica) y los tiempos de duplicación de la microbiota que puede desarrollarse en esas condiciones. Por esta razón, las atmósferas modificadas prolongan la vida útil de la carne de pavo.

\section{Bacterias lácticas}

Como va a comprobarse, la composición de la microbiota láctica fue variable. De acuerdo con esto, se observaron diferencias entre los niveles iniciales de bacterias lácticas en los lotes almacenados a 1 y $7^{\circ} \mathrm{C}$.
A grandes rasgos, las fases de latencia de las bacterias lácticas aumentaron conforme la atmósfera se hacía más selectiva. Este efecto se comprobó más claramente a 1 que a $7^{\circ} \mathrm{C}$.

Esta microbiota no se vio afectada de una forma significativa por las atmósferas aquí estudiadas o, en otras palabras, las bacterias lácticas fueron resistentes al $\mathrm{CO}_{2}$, como ya han constatado repetidamente innumerables autores (p.e. Farber, 1991 ; Parry, 1993 ; Sørheim et al.,' 1995 ; Brody, 1996). Compárense los tiempos de duplicación de las bacterias lácticas desarrolladas a $7^{\circ} \mathrm{C}$ : 0,6 días en aire, $\mathrm{N}_{2}$ y $20 / 80 \mathrm{CO}_{2} /$ $\mathrm{O}_{2}$ y 1,2 en $40 / 60 \mathrm{CO}_{2} / \mathrm{O}_{2}$. Estas cifras son tan parecidas que permiten afirmar que estas bacterias se desarrollan por igual en todas esas atmósferas, excepto, quizás, en la última.

En algunos lotes se observaron notables diferencias en los tiempos de duplicación de las bacterias lácticas, como en la envasada en aire y $\mathrm{N}_{2}$ y mantenida a $1^{\circ} \mathrm{C}$ (Tabla 1). El por qué de estas variaciones puede radicar en que, dado el escaso desarrollo de esta microbiota en esas condiciones (Figura 1), el método de cálculo no proporciona resultados tan precisos como cuando existe un crecimiento más abundante.

En resumen, puede afirmarse que las bacterias lácticas pueden crecer en todas las atmósferas aquí estudiadas, con unas velocidades similares. Además, puede decirse que debido al $\mathrm{pH}$ elevado de la carne, crecen mejor otros microorganismos que, posiblemente, dificultan el desarrollo de la microbiota láctica. Cuando las bacterias lácticas prevalecen en la carne pueden cooperar en la prolongación de su vida útil merced a diversos mecanismos.

\section{Microorganismos desarrollados en agar VRBG}

Este medio se emplea para la enumeración presuntiva de Enterobacteriaceae en alimentos (Oxoid, 1996); por lo que los datos obtenidos de los recuentos aquí efectuados se van a considerar enterobacterias, aunque no pueda garantizarse que todos los microorganismos que se desarrollan en este medio lo sean. No obstante, la gran mayoría de los microbiólogos lo usan para este fin.

Los recuentos en el día 0 en los lotes fluctuaron entre unas cifras cercanas a $10^{2}$ ufc/cm² (Tablas 1 y 2 ). En ningún caso las enterobacterias predominaron al principio de las experiencias.

La atmósfera fue decisiva para el crecimiento de esta microbiota. Como era de esperar, las enterobacterias crecieron en aire sin dificultades, tanto a 1 como a $7^{\circ} \mathrm{C}$, alcanzando tasas elevadas en fase estacionaria (Tablas 1 y 2).

En $\mathrm{N}_{2}$ también se detectó su desarrollo en las dos temperaturas. De todas formas, el crecimiento de las enterobacterias en $\mathrm{N}_{2}$ fue siempre significativamente menor que el detectado en aire (Tablas 1 y 2). Otros autores han detectado crecimientos abundantes de enterobacterias en carne de vacuno (Fu et al., 1992) envasada a vacío. 
A $1^{\circ} \mathrm{C}$, las atmósferas enriquecidas en $\mathrm{CO}_{2}$ inhibieron claramente el desarrollo de las enterobacterias. Se detectó su desarrollo tanto con el $20 \%$ de $\mathrm{CO}_{2}$ como con el 40 , aunque el crecimiento fue mucho más restringido con el porcentaje más elevado (Tabla 1).

En cambio, a $7^{\circ} \mathrm{C}$, las enterobacterias se desarrollaron con cierta facilidad, ya que se detectó su multiplicación tanto en $20 / 80 \mathrm{CO}_{2} / \mathrm{O}_{2}$ como en $40 / 60 \mathrm{CO}_{2} / \mathrm{O}_{2}$, aunque el crecimiento siempre fue más lento y alcanzó tasas menores en fase estacionaria en esta última atmósfera (Tabla 2). Estos datos indican que las enterobacterias son sensibles al $\mathrm{CO}_{2}$, como ya habían afirmado, entre otros, McMullen y Stiles (1991), Fu et al. (1992) y Sawaya et al. (1995).

De los resultados relativos a las enterobacterias cabría decir que estos microorganismos pueden desarrollarse con cierta facilidad en ambientes con bajas tensiones de $\mathrm{O}_{2}$ (vacío, $100 \%$ de $\mathrm{N}_{2}$ ) y que son muy sensibles al $\mathrm{CO}_{2}$ siempre y cuando el almacenamiento se haga a una temperatura de refrigeración baja.

\section{Brochothrix thermosphacta}

Dadas la composición del medio de cultivo STAA y las condiciones de incubación, puede decirse que prácticamente todas las unidades formadoras de colonia desarrolladas corresponden a la especie $B$. thermosphacta. A tal efecto, López-Gálvez et al. (1997) aseguran que este medio es totalmente selectivo para esta bacteria, pero que pueden contarse menos células de las que en realidad existen debido al carácter inhibitorio de las sustancias (sulfato de estreptomicina, cicloheximida y acetato de talio) añadidas al medio.

Las tasas iniciales de esta bacteria fueron bastante bajas (menos de 35 ufc/cm²).

Esta bacteria se desarrolló en todas las experiencias en los filetes envasados en aire, tanto a 1 como a $7^{\circ} \mathrm{C}$, aunque, como era de esperar, se multiplicó más rápidamente a la temperatura más elevada. También creció al envasarla en $100 \%$ de $\mathrm{N}_{2}$ con un comportamiento similar, respecto a la temperatura de almacenamiento, al observado en aire. La comparación de los parámetros de crecimiento en estas dos atmósferas permiten decir que esta bacteria se desarrolla mejor en condiciones aerobias. Otros autores también han observado crecimiento de esta bacteria en pollo envasado en $100 \%$ de $\mathrm{N}_{2}$ y a vacío (Kakouri y Nychas, 1994), en carne de cerdo envasada a vacío (Gill y Harrison, 1989 ; Taylor et al., 1990) y en carne de vacuno en $100 \%$ de $\mathrm{N}_{2}$ (Nissen et al., 1996) y a vacío (Taylor et al., 1990 ; Penney et at., 1993).

Es bien conocida la relativa resistencia de $B$. thermosphacta al $\mathrm{CO}_{2}$ (Rönner, 1994), pero se ha comprobado en este trabajo que la inclusión de este gas en la atmósfera ralentiza el crecimiento de la bacteria. De todas formas, cuando la temperatura de almacenamiento fue $7^{\circ} \mathrm{C}$ este microorganismo se multiplicó en todas las experiencias aquí realizadas. Se ha comprobado que la acción combinada del $\mathrm{CO}_{2}$ y bajas temperaturas de almacenamiento $\left(1^{\circ} \mathrm{C}\right)$ impiden el desarrollo de esta bacteria. El efecto combinado de $\mathrm{CO}_{2}$ y bajas temperaturas confirma los hallazgos de Blickstad y Molin (1983) y Gill y Harrison (1989). De esto puede deducirse que el crecimiento de esta bacteria es posible en ausencia de $\mathrm{O}_{2}$, pero parece necesitar este gas para crecer en presencia de $\mathrm{CO}_{2}$. De todas formas, debe quedar claro que, en este trabajo, B. thermosphacta creció mejor en aerobiosis, después en $100 \%$ de $\mathrm{N}_{2}, 20 / 80 \mathrm{CO}_{2} / \mathrm{O}_{2} \mathrm{y}$, finalmente, en $40 / 60 \mathrm{CO}_{2} / \mathrm{O}_{2}$, como puede deducirse de la comparación de los parámetros de crecimiento de este microorganismo, recogidos en las Tablas 1 y 2 .

Puede decirse por tanto, que $B$. thermosphacta forma parte prácticamente siempre de la microbiota contaminante de la carne. Esta bacteria se multiplica en presencia de $\mathrm{O}_{2}$ incluso con cantidades pequeñas (inferiores al $5 \%$ ) y puede llegar a ser el agente causal de la alteración de la carne. De todas formas, el desarrollo de esta bacteria es inhibido, aunque no impedido, por la presencia de elevados porcentajes de $\mathrm{CO}_{2}$.

\section{Microbiota desarrollada en agar PSD}

Al igual que en los otros medios, no se identificaron los microorganismos desarrollados en este medio de cultivo, por lo que no puede garantizarse que todos ellos pertenezcan al género Pseudomonas. Los recuentos en este medio hay que interpretarlos con suma cautela. Los autores de su formulación (Mead y Adams, 1977) indicaron en el título del trabajo original que es un medio selectivo para el aislamiento rápido de pseudomonadaceas de carne de ave alterada. Sin embargo, un estudio detallado del artículo permite concluir que la selectividad de dicho medio mejora la de otros, que existían en aquél entonces y, en comparación con ellos, evitaba el crecimiento de Aeromonas spp. Sin embargo, en el agar PSD se desarrollaba, con la misma facilidad que las Pseudomonas, Shewanella putrefaciens (entonces clasificada como Alteromonas putrefaciens), lo que, no cabe duda, es una interferencia digna de mención, ya que el hábitat de ésta y aquéllas es el mismo. Por otra parte, los autores del medio concluyeron en su artículo que no es un medio totalmente selectivo para pseudomonas, particularmente cuando la cantidad de estos microorganismos es escasa en comparación con la de otros géneros; no obstante es el medio más adecuado para el aislamiento de pseudomonas de alimentos en los que el número de pseudomonas es presumiblemente elevado. En cualquier caso, son muchos los autores (McMullen y Stiles, 1991 ; Kakouri y Nychas, 1994 ; Sørheim et al., 1995 ; Nissen et al., 1996) que lo han utilizado y utilizan como medio selectivo de recuento de pseudomonas con incubación a $20-25^{\circ} \mathrm{C}$ y recuento a las $48-36 \mathrm{~h}$. 
Ante estos comentarios, sostenemos que el agar PSD no es un medio selectivo pero sí muy favorable para el aislamiento $y$, probablemente, para el recuento de pseudomonas siempre que se trabajen con muestras procedentes de hábitats donde dichos microorganismos pueden crecer activamente, es decir, en aerobiosis. Sin embargo, no es tan eficaz si las muestras proceden de entornos anóxicos (vacío o atmósfera de $100 \%$ de nitrógeno) o enriquecidas en $\mathrm{CO}_{2}$.

Al principio se desarrollaron colonias en agar PSD, que pudieran ser pseudomonas (Figuras 1 y 2). En las dos temperaturas esta microbiota fue la dominante (Tablas $1 \mathrm{y}$ 2), excepto en nitrógeno y $40 / 60 \mathrm{CO}_{2} / \mathrm{O}_{2}$ a $7^{\circ} \mathrm{C}$. Lógicamente, estas diferencias se deben al carácter aleatorio de la contaminación inicial de las muestras.

Como era de esperar, las pseudomonas se multiplicaron activamente en las carnes envasadas aeróbicamente y siempre formaron parte de la microbiota dominante al final del periodo de almacenamiento, casi siempre en solitario (Tablas 1 y 2 ).

En la atmósfera de nitrógeno se observó crecimiento en todos los casos, llegando a tasas muy elevadas en fase estacionaria (Tablas 1 y 2 ). A pesar del carácter de aerobias estrictas de las pseudomonas, Hood y Mead (1993) afirman que pueden multiplicarse en atmósferas modificadas con bajas tensiones de $\mathrm{O}_{2}$, del orden del $1 \%$ en la atmósfera, por lo que las colonias aparecidas pueden pertenecer al género Pseudomonas o a los otros grupos microbianos citados anteriormente, ya que la atmósfera con $100 \%$ de $\mathrm{N}_{2}$ puede contener una cantidad de $\mathrm{O}_{2}$ residual suficiente para soportar su desarrollo, pero no detectable con la metodología empleada para la medida de los gases. Ya en 1986, Gill afirmó que las pseudomonas podrían multiplicarse en atmósferas modificadas supuestamente anaerobias debido a la dificultad de eliminar totalmente el $\mathrm{O}_{2}$. Otros autores también han detectado cierto desarrollo de pseudomonas en carne de pato envasada a vacío y almacenada a $2^{\circ} \mathrm{C}$ (Barnes et al., 1979) y en carne de pollo envasada en las mismas atmósferas y almacenada a $3^{\circ} \mathrm{C}$ (Kakouri y Nychas, 1994). Todos estos autores ofrecen recuentos bastante escasos en estas atmósferas; es decir, las pseudomonas están inhibidas por la reducida tensión de $\mathrm{O}_{2}$, pero aún pueden multiplicarse.

En este trabajo se apreció el desarrollo de los microorganismos que crecen en agar PSD en muestras envasadas en atmósferas enriquecidas en $\mathrm{CO}_{2} / \mathrm{O}_{2}$, y recuentos en fase estacionaria incluso por encima de $10^{7}$ ufc/ $\mathrm{cm}^{2}$ (Tabla 2). El hecho de haberse observado crecimiento en carne de pavo $(\mathrm{pH} 6,0)$ induce a pensar que el microorganismo responsable de dicho recuento fuera Shewanella putrefaciens, ya que esta bacteria se multiplica en carne refrigerada $\left(<4^{\circ} \mathrm{C}\right) \mathrm{con} \mathrm{pH}$ elevado (Hood y Mead, 1993). Además, es la única bacteria de las ensayadas por Mead y Adams (1977) que crecía perfectamente, igual que las pseudomonas, en agar PSD.

En resumen, las pseudomonas, como aerobias estrictas, se desarrollan extraordinariamente bien en aire, siendo las responsables de la alteración de la carne en aerobiosis, mientras que en anaerobiosis (atmósfera de nitrógeno) 0 en atmósferas enriquecidas en $\mathrm{CO}_{2} / \mathrm{O}_{2}$ pueden detectarse de forma ocasional.

\section{Conclusiones}

De acuerdo con los resultados obtenidos, puede concluirse que:

La vida útil de la carne de pavo refrigerada se duplica, como mínimo, al mantenerla en atmósferas enriquecidas en $\mathrm{CO}_{2}$.

Al aumentar el porcentaje de $\mathrm{CO}_{2}$ en la atmósfera, se prolonga la fase de latencia y se ralentiza la velocidad de crecimiento microbiano en general.

Las atmósferas enriquecidas en dióxido de carbono son más eficaces que la de nitrógeno y, obviamente, las fases de latencia son más cortas y las velocidades de crecimiento más rápidas a 7 que a $1^{\circ} \mathrm{C}$.

\begin{abstract}
The objective of the present study was to evaluate the effect of modified atmospheres on refrigerated turkey breast meat and the behavior of microorganisms responsible of its spoilage. Turkey breast was cut into ca. $1 \mathrm{~cm}$ thick slices of $9 \mathrm{~cm}^{2}$, introduced in Cryovac type BB4L bags, characterized by its low gas permeability, and divided in four batches. The bags of each batch were filled with either $1.5 \mathrm{~L}$ of air $(100 \%)$, nitrogen $(100 \%), \mathrm{CO}_{2} / \mathrm{O}_{2}(20 / 80)$ or $\mathrm{CO}_{2} / \mathrm{O}_{2}(40 / 60)$ and finally sealed. Samples were subdivided in two batches and stored in walk-in cold rooms at 1 and $7^{\circ} \mathrm{C}$. Samples were taken at different days of storage and $\mathrm{pH}$ and gas concentration $\left(\mathrm{CO}_{2} / \mathrm{O}_{2} / \mathrm{N}_{2}\right)$ were determined. Likewise, total viable, lactic acid bacteria, Enterobacteriaceae, Brochothrix thermosphacta and Pseudomonas were counted. Bacterial growth parameters were assessed using Gompertz equations. As expected, modified atmosphere packaged extend the turkey shelf-life. In nitrogen atmosphere, shelf-life increased 5 days, regardless of stored temperature. The inhibitory effect was more marked under $\mathrm{CO}_{2} / \mathrm{O}_{2}$ atmosphere at $1^{\circ} \mathrm{C}$. Bag gas content was fairly constant until meat was spoiled, when a decrease of $\mathrm{O}_{2}$ and increase of $\mathrm{CO}_{2}$ was observed. $\mathrm{pH}$ was constant during storage time in samples packaged in modified atmosphere. At 1 and $7^{\circ} \mathrm{C}$ it was also observed a progressive increase of lag phase and duplication time when samples were stored in air $(100 \%)$, nitrogen (100\%), $\mathrm{CO}_{2} / \mathrm{O}_{2}(20 / 80)$ or $\mathrm{CO}_{2} / \mathrm{O}_{2}(40 / 60)$ respectively. It may be concluded that modified atmosphere packaging, at both temperature assayed, inhibited spoilage microorganisms growth on turkey meat extending the shelflife, mainly in $\mathrm{CO}_{2}$ enriched atmospheres.
\end{abstract}

Keywords: modified atmospheres; turkey meat; shelf-life. 


\section{Agradecimientos}

Los autores agradecen a: Comisión Interministerial de Ciencia y Tecnología (CICYT), proyecto ALI 94-0350; "AAIR Concerted Action PL-920630 Physiology Food Poisoning Microorganisms" y; CAPES DAFA - Gobierno de Brasil.

\section{Referências bibliográficas}

AVERY, S. M., ROGERS, A. R., BELL, G. Continued inhibitory effect of carbon dioxide packaging on Listeria monocytogenes and other microorganisms on normal $\mathrm{pH}$ beef during abusive retail display. Int. J. Food Sci. Technol. n. 30, p. $725-735,1995$.

BARNES, E. M., IMPEY, C. S., GRIFFITHS, N. M. The spoilage flora and shelf-life of duck carcasses stored at 2 or $-1^{\circ} \mathrm{C}$, in oxygen permeable, or oxygen impermeable film. British Poultry Science n. 20, p. 491-500, 1979.

BLICKSTAD, E.; MOLIN, G. Carbon dioxide as a controller of the spoilage of pork, with special reference to temperature and sodium chloride. J. Food Prot. n. 46, p. 756-763, 1983.

BRODY, A. L. Envasado de alimentos en atmósferas controladas, modificadas y a vacío (ed. Brody, A. L.). Acribia, Zaragoza/España. 1996.

CLARK, D. S., LENTZ, C. P. Use of mixtures of carbon dioxide and oxygen for extending shelf-life of pre-packaged fresh beef. Can. Inst. Food Sci. Technol. J., n. 6, p. 194-196, 1973.

DAINTY, R. H., SHAW, N. G., ROBERTS, T. A. Microbial and chemical changes in chill stored red meats. Em: Food Microbiology: Advances and Prospects. (eds. Roberts, T. A. y Skinner, F. A.) Academic Press Inc., London, p: 151-178, 1983.

DANIELS, J. A., KRISHNAMURTHI, R., RIZVI, S. S. H. A review of effects of carbon dioxide on microbial growth and food quality. J. Food Prot., n. 48, p. 532-537, 1985.

DOHERTY, A., SHERIDAN, J. J., ALLEN, P., MCDOWELL, D. A., BLAIR, Y. S., HARRINGTON, D. Growth of Yersinia enterocolitica $\mathrm{O}: 3$ on modified atmosphere packaged lamb. Food Microbiol., n. 12, p. 251-157, 1995.

Survival and growth of Aeromonas hydrophila on modified atmosphere packaged normal and high $\mathrm{pH}$ lamb. Int. J. Food Microbiol., n. 28, p. 379-392, 1996.

ENFORS, S. O., MOLIN, G., TERNSTRÖM, A. Effect of packaging under carbon dioxide, nitrogen or air on the microbial flora of pork stored at $4^{\circ}$ C. J. Appl. Bacteriol., n. 47, p. 197-208, 1979.

FANG, T. J., LIN, L. W. Growth of Listeria monocytogenes and Pseudomonas fragi on cooked pork in a modified atmosphere packaging/nisin combination system. J. Food Prot., 57, p. 479-485, 1994.

FARBER, J. M. Microbiological aspects of modified-atmosphere packaging technology - A review. J. Food Prot., 54, p. 58-70, 1991.

FARRAG, S. A., MARTH, E. H. Behaviour of Listeria monocytogenes when incubated together with Pseudomonas species in tryptose broth at 7 and $13^{\circ} \mathrm{C}$. J. Food Prot. n. 52, p. 536-539, 1989.

FEY, M. S., REGENSTEIN, J. M. Extending shelf-life of fresh, wet, red hake and salmon using $\mathrm{CO}_{2}-\mathrm{O}_{2}$ modified atmosphere and potassium sorbate ice at $1^{\circ} \mathrm{C}$. J. Food Sci., n. 47, p. 1048-1054, 1982.
FU, A. H., MOLINS, R. A., SEBRANEK, J. G. Storage quality characteristics of beef rib eye steaks packaged in modified atmospheres. J. Food Sci., n. 57, p. 283-287, 1992.

GIBSON, A. M., BRATCHELL, N., ROBERTS, T. A. The effect of sodium chloride and temperature on the rate and extent of growth of Clostridium botulinum type $\mathrm{A}$ in pasteurised pork slurry, J. Appl. Bacteriol., n. 62, p. 479-490, 1987.

GILL, C. O. Microbial interactions with meats. Em: Meat Microbiology (ed. Brow, M. D.). Applied Sci. Publishers, London, p. 225-264, 1982.

. The control of microbial spoilage in fresh meats. Em: Advances in meat research. Meat and poultry microbiology - Vol. 2 (eds. Pearson, A. M. and Dutson, T. R.). AVI Publishing Co., Inc., Westport, CT. London, p. 49-88, 1986.

HARRISON, C. L. The storage life of chilled pork packaged under carbon dioxide. Meat Sci., n. 24, p. 313324, 1989.

HOLLAND, G. C. Proc. Meat Ind. Res. Conf., Chicago, IL, USA, p. 21, 1980.

HOOD, D. E.; MEAD, G. C. Modified atmosphere storage of fresh meat and poultry. In: Principles and Applications of Modified Atmosphere Packaging of Food (ed. Parry, R. T.). Blackie Academic \& Professional, London, p. 269-298, 1993.

HOTCHKISS, J. H., BAKER, R. C., QURESHI, R. A. Elevated carbon dioxide atmospheres for packaging poultry. II. Effects of chicken quarters and bulk packages. Poultry Sci., n. 64, p. 333, 1985.

KAKOURI, A., NYCHAS, G. J. E. Storage of poultry meat under modified atmospheres or vacuum packs: possible role of microbial metabolites as indicator of spoilage. J. Applied Bacteriol., n. 76, p. 163-212, 1994.

LÓPEZ-GÁVEZ, D., HOZ, L. de la, BLANCO, M., ORDÓÑEZ, J. A. 1998 . En prensa.

LÓPEZ-GÁVEZ, D., HOZ, L.de la, ORDÓÑEZ, J. A. Effect of carbon dioxide and oxygen enriched atmospheres on microbiological and chemical changes in refrigerated tuna (Thunnus alalunga) steaks. J. Agric. Food Chem., n. 43, p. 483-490, 1995.

LÓPEZ-LORENZO, P., HERNANDEZ, P., SANZ, B., ORDÓÑEZ, J. A. Effect of oxygen- and carbon dioxide-enriched atmospheres on shelf-life extension of refrigerated ground pork. Meat Sci., n. 4, p. 89-94, 1980.

MAN, J.C. de, ROGOSA, M., SHARPE, M. E. A medium for the cultivation of Lactobacilli. J. Appl. Bacteriol., n. 23, p. 130135, 1960.

MANU-TAWIAH, W., MYERS, D. J., OLSON, D. G., MOLINS, R. A. Survival and growth of Listeria monocytogenes and Yersinia enterocolitica in pork chops packaged under modified gas atmospheres. J. Food Sci., n. 58, p. 475-479, 1993.

MARSHALL, D. L., WIESE-LEHIGH, P. L., WELLS, J. H., FARR, A. J. Comparative growth of Listeria monocytogenes and Pseudomonas fluorescens on precooked chicken nuggets stored under modified atmospheres. J. Food Prot., n. 54, p. $841-843,851,1991$. 
MCMEEKIN, T. A. Microbial spoilage of meats. In: Developments in Food Microbiology. Vol. 1 (ed. Davies, R.). Applied Sci. Publishers, London, p. 1-40, 1982.

McMULLEN, L. M.; STILES, M. E. Changes in microbial parameters and gas composition during modified atmosphere storage of fresh pork loin chops. J. Food Prot., n. 54, p. 778-783, 1991.

MEAD, G. C. Effect of packaging and gaseous environment on the microbiolpgy and shelf life processed poultry products. In: Food Microbiology: Advances and Prospects (eds. Roberts, T. A. e Skinner, F. A.). Academic Press, London, p. 203-216, 1983.

MEAD, G. C., ADAMS, B. W. A selective medium for the rapid isolation of pseudomonads associated with poultry meat spoilage. Br. Poult. Sci., n. 18, p. 661-670, 1977.

NEWTON, K. G., HARRISON, J. C. L., SMITH, K. M. The effect of storage in various gaseous atmospheres on the microflora of lamb chops held at 1으. J. Applied Bacteriol., 43, p. 53-60, 1977.

NISSEN, H., SØRHEIM, O., DAINTY, R. Effects of vacuum, modified atmospheres and storage temperature on the microbial flora of packaged beef. Food Microbiol., n. 13, p. 183-191, 1996.

ORDÓÑEZ, J. A., LEDWARD, D. A. Lipid and myoglobin oxidation in pork stored in oxygen - and carbon dioxide enriched atmospheres. Meat Sci., n. 1, p. 41, 1977.

OXOID 1996. Catálogo de Microbiología. Unipath.

PARRY, Introduction. Em: Principles and Applications of Modified Atmosphere Packaging of Food. (ed. Parry, R. T.). Blackie Academic \& Professional, London, p. 1-18, 1993.

PENNEY, N., HAGYARD, C. J., BELL, R. G. Extension of shelflife of chilled slice roast beef by carbon dioxide packaging. Int. J. Food Sci. Technol., n. 28, p. 181-191, 1993.
RÖNNER, U. Modified atmosphere packaging of non-respiring products. Em: Food Preservation by Combined Processes. (eds. Leistner, L. y Gorris, L. G. M.). Final Report. FLAIR (Food Linked Agro-Industrial Research) Concerted Action No. 7, Subgroup B, p. 51-58, 1994.

SAWAYA, W. N., ELNAWAWY, A. S., ABU-RUWAIDA, A. S., KHALAFAWI, S. y DASHTI, B. Influence of modified atmosphere packaging on shelf-life of chicken carcasses under refrigerated storage conditions. J. Food Safety, n. 15, p. 35-51, 1995.

SEIDEMAN, S. C., VANDERZANT, C., SMITH, G. C., DILL, C. W. y CARPENTER, Z. L. Appearance of beef, pork and lamb stored in vacuum or modified gas atmospheres. J. Food Prot., n. 43, p. 252-258, 1980.

SHERIDAN, J. J., DOHERTY, A., ALLEN, P., MCDOWELL, D. A., BLAIR, Y. S. y HARRINGTON, D. Investigations on the growth of Listeria monocytogenes on lamb packaged under modified atmospheres. Food Microbiol., n. 12, p. 259-266, 1995.

SØRHEIM, O., GRINI, J. A., NISSEN, H., ANDERSEN, H. J. y LEA, P. Pork loins stored in carbon dioxide. Colour and microbiological shelf life. Fleischwirtsch.(English part) n. 75, p. 679-681, 1995.

SPAHL, A., REINECCIUS, G. y TATINI, S. Storage life of pork chops in $\mathrm{CO}_{2}$-containing atmospheres. J. Food Prot., n. 44, p. $670-673,1981$.

TAYLOR, A. A. Y MCDOUGALL, D. B. Fresh beef packages in mixtures of oxygen and carbon dioxide. J. Food Technol., n. 8, p. 453-461, 1973.

TAYLOR, A. A., DOWN, N. F. y SHAW, B. G. A comparison of modified atmosphere and vacuum skin packing for the storage of red meats. Int. J. Food Sci. \& Technol., n. 25, p. 98-109, 1990. 